To the Editors:

\title{
Advertisement on paracetamol in Sri Lanka Journal of Child Health 2003; 32(2)
}

Sri Lanka Journal of Child Health, 2003; 32: 84

(Key words: paracetamol, child)

I wish to bring to your kind attention that the advertisements about paracetamol (Panadol for Children) in your journal are misleading the readers. There is a page telling lack of hepatic injury after acute paracetamol doses of up to $200 \mathrm{mg} / \mathrm{kg}$ in children. In that page there is a section in bold stating "On the basis of these data, paediatric patients with acute acetaminophen (paracetamol) exposures of up to $200 \mathrm{mg} / \mathrm{kg}$, treated with home monitoring alone, do not develop signs and symptoms of hepatic injury".

It is my understanding that although sporadic cases are seen, acute paracetamol overdose of healthy children is not a problem in Sri Lanka. It is widely accepted that doses above $150 \mathrm{mg} / \mathrm{kg}$ could be fatal and that such cases need in-hospital observation and treatment with antidotes. I wonder whether the advertiser is recommending home management of these patients!

The advertisement in the page immediately following the above is about choosing a suitable analgesic (i.e. paracetamol) for children.

The problem that has been highlighted with use of paracetamol in the past in Sri Lanka is the hepatotoxicity seen with its use in children with fever (undiagnosed fever, viral fever). In these children extreme care is needed in deciding on the dose of paracetamol. The general recommendation is not to exceed doses beyond $80 \mathrm{mg} / \mathrm{kg} /$ day. Unfortunately this issue is not highlighted in the advertisement. It does not highlight the dose restriction when used as an antipyretic. A reader can easily get misled to believe that paracetamol in doses of $200 \mathrm{mg} / \mathrm{kg}$ are safe as an antipyretic. Even in section on fever in children the emphasis is on drug management of fever. The beneficial aspects on fever are not mentioned either.
I think the Editors have a responsibility to check what is there in the advertisements that are appearing in their Journal. I have to say that this aspect has been deficient on this occasion.

The advertisers also should resort to "responsible advertising" and in my opinion they too have been irresponsible. There is an organization called "Panadol Information Centre". I wonder what this organization has to say about this advertisement.

I think the Editors of the Sri Lanka Journal of Child Health should give equal publicity to my letter in their next issue.

\section{R L Jayakody}

Head, Department of Pharmacology, Faculty of Medicine, University of Colombo. 
